SHORT REPORT

\title{
Guidelines and adenosine dosing in supraventricular tachycardia
}

\author{
J Dixon, K Foster, J Wyllie, C Wren
}

Arch Dis Child 2005;90:1190-1191. doi: 10.1136/adc.2005.077636

This retrospective review of present practice of administration of adenosine by paediatricians shows that current guidelines recommend starting doses that are effective in only $9 \%$ of infants and children.

of ntravenous adenosine is the first line drug for termination of supraventricular ventricular tachycardia in infants and children. The latest edition of the Royal College of Paediatrics and Child Health (RCPCH) publication, Medicines for children, recommends an initial dose of $50 \mu \mathrm{g} / \mathrm{kg}$ followed by increments of $50 \mu \mathrm{g} / \mathrm{kg}$ up to a maximum of $300 \mu \mathrm{g} / \mathrm{kg}$ in infants and $500 \mu \mathrm{g} / \mathrm{kg}$ in children. ${ }^{1}$ Current Advanced Paediatric Life Support (APLS) guidelines recommend incremental doses of 50, 100, and $250 \mu \mathrm{g} / \mathrm{kg} .{ }^{2}$ The Pediatric Advanced Life Support (PALS) guidelines recommend a first dose of $100 \mu \mathrm{g} / \mathrm{kg}$ followed by a second dose of $200 \mu \mathrm{g} / \mathrm{kg}$ if necessary. ${ }^{3}$ Because of these varying recommendations, we investigated the success of various doses of adenosine in terminating supraventricular tachycardia in infants and children in our population.

\section{METHODS}

We conducted a retrospective review of consecutive infants and children with supraventricular tachycardia referred to this unit between January 1998 and May 2003, where intravenous adenosine was given in the local paediatric hospital prior to discussion with, or referral to, this hospital. Adenosine was given to 35 patients (23 infants and 12 children) with 53 episodes of supraventricular tachycardia. Details of the initial dose of adenosine and all subsequent incremental doses administered in the local paediatric department were obtained from local hospital patient records, and the success in terminating in tachycardia was noted. Body weight was recorded and doses were adjusted to $\mu \mathrm{g} / \mathrm{kg}$. The study was approved by the Newcastle upon Tyne Hospitals NHS Trust Research \& Development Directorate.

\section{RESULTS}

Adenosine was given to 23 infants with 32 episodes of supraventricular tachycardia. Their ages ranged from 1 to 72 days. The initial dose given was $50-200 \mu \mathrm{g} / \mathrm{kg}$ with a median of $100 \mu \mathrm{g} / \mathrm{kg}$ and a mean of $115 \mu \mathrm{g} / \mathrm{kg}$ (fig 1). A dose of $50 \mu \mathrm{g} / \mathrm{kg}$ was effective in only $9 \%$ of patients and $150 \mu \mathrm{g} / \mathrm{kg}$ was effective in $35 \%$ of infants (fig 2). The median effective dose was $200 \mu \mathrm{g} / \mathrm{kg}$. There were no significant complications associated with adenosine administration.

Adenosine was given to 12 children with 21 episodes of supraventricular tachycardia. Their ages ranged from 17 months to 15 years and the initial dose ranged from 50 to 150 $\mu \mathrm{g} / \mathrm{kg}$ with a median first dose of $50 \mu \mathrm{g} / \mathrm{kg}$ and a mean of $73 \mu \mathrm{g} / \mathrm{kg}$ (fig 1). The effective dose ranged from 50 to $300 \mu \mathrm{g} /$ $\mathrm{kg}$ (fig 2). A dose of $50 \mu \mathrm{g} / \mathrm{kg}$ was effective in only $9 \%$ and the median effective dose was $150 \mu \mathrm{g} / \mathrm{kg}$. Tachycardia was terminated in all patients. Minor side affects were observed but not analysed. No significant adverse affects were recorded.

\section{DISCUSSION}

Adenosine is widely accepted as the first line treatment for supraventricular tachycardia in infants and children but current guidelines offer confusing advice about dosage. Early reports used experimental protocols with starting doses of $37.5 \mu \mathrm{g} / \mathrm{kg}^{4}$ and $50 \mu \mathrm{g} / \mathrm{kg}^{5}{ }^{5}$ Overholt and colleagues ${ }^{4}$ reported a mean effective dose of $114-131 \mu \mathrm{g} / \mathrm{kg}$ depending on the precise diagnosis, and Till and colleagues ${ }^{5}$ found a median effective dose of $150 \mu \mathrm{g} / \mathrm{kg}$. Despite this, current protocols advise starting doses of 50 or $100 \mu \mathrm{g} / \mathrm{kg}$.

Our study has shown that a dose of $50 \mu \mathrm{g} / \mathrm{kg}$ is effective in $<10 \%$ of infants and children and $100 \mu \mathrm{g} / \mathrm{kg}$ is effective in $<25 \%$ of infants and $<50 \%$ of children. A dose of $150 \mu \mathrm{g} / \mathrm{kg}$ is more effective in children (around $80 \%$ ) than in infants (around 35\%). This difference may be explained by the difference in weight to body surface area ratio and there might be little difference if adenosine was prescribed and administered in $\mathrm{mg} / \mathrm{m}^{2}$ rather than $\mu \mathrm{g} / \mathrm{kg}$. Other possible explanations for the lower response in infants include smaller cannulae limiting the injection rate and the fact that babies tend to be more ill at presentation and may have prolonged circulation times.

Other studies have shown the lack of efficacy of small adenosine doses: Sherwood and colleagues ${ }^{6}$ reported a $16 \%$ response to $50 \mu \mathrm{g} / \mathrm{kg}$ and Losek and colleagues ${ }^{7}$ showed a $22 \%$ efficacy for doses of up to $100 \mu \mathrm{g} / \mathrm{kg}$. The latter report also showed that significantly more doses need to be administered when the first dose is low. One danger of too low a starting dose is that parents and paediatricians lose confidence in what is a very effective drug. We and others have found no significant adverse affects when giving adenosine in therapeutic doses.

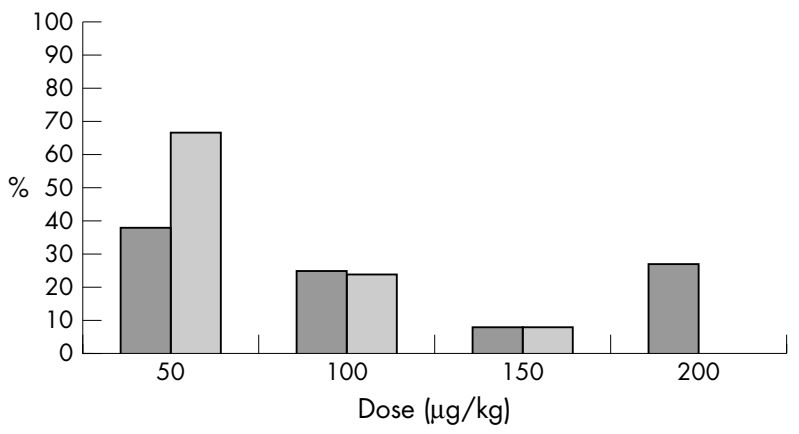

Figure 1 Proportion of infants (dark grey bars) and children (light grey bars) receiving stated doses of adenosine. 


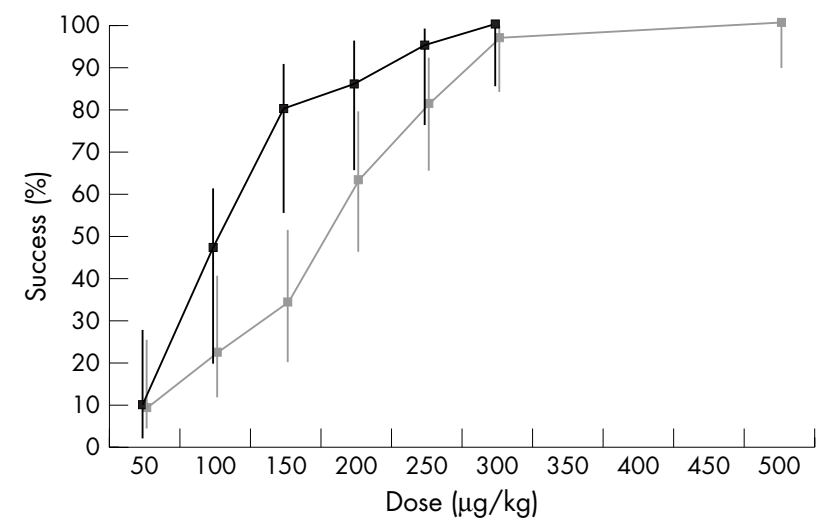

Figure 2 Cumulative efficacy of adenosine in terminating tachycardia in infants (grey line) and children (black line). Error bars show 95\% confidence intervals.

We conclude that the current recommended starting doses of adenosine are too low. It seems inappropriate to give a dose which has a less than $10 \%$ chance of being effective. The minimum dose ought to be no less than $100 \mu \mathrm{g} / \mathrm{kg}$ in children and 150 or $200 \mu \mathrm{g} / \mathrm{kg}$ in infancy.

\section{Authors' affiliations \\ J Dixon, K Foster, J Wyllie, C Wren, Department of Paediatric \\ Cardiology, Freeman Hospital, Newcastle upon Tyne, UK \\ Competing interests: none declared}

Correspondence to: Dr C Wren, Department of Paediatric Cardiology, Freeman Hospital, Newcastle upon Tyne NE7 7DN, UK; Christopher. Wren@nuth.nhs.uk

Accepted 3 July 2005

\section{REFERENCES}

1 RCPCH. Medicines for children, 2nd edn. London: RCPCH Publications Limited, 2003.

2 Mackway-Jones K, Molyneux E, Phillips B, Wieteska S, eds. Advanced paediatric life support. The practical approach, 3rd edn. London: BMJ Books, 2001.

3 Anon. ECC guidelines. Part 10: Pediatric Advanced Life Support. Circulation 2000;102(suppl I):I-291-I-342.

4 Overholt ED, Rheuban KS, Gutgesell HP, et al. Usefulness of adenosine for arrhythmias in infants and children. Am J Cardiol 1988;61:336-40.

5 Till J, Shinebourne EA, Rigby ML, et al. Efficacy and safety of adenosine in the treatment of supraventricular tachycardia in infants and children. Heart 1989:62:204-11.

6 Sherwood MC, Lau KC, Sholler GF. Adenosine in the management of supraventricular tachycardia in children. J Paediatr Child Health 1998;34:53-6.

7 Losek JD, Endom E, Dietrich A, et al. Adenosine and pediatric supraventricular tachycardia in the emergency department: multicenter study and review. Ann Emerg Med 1999;33:185-91.

\section{IMAGES IN PAEDIATRICS}

\section{A memorable stay}

$\mathrm{T}$

his 7 year old boy was admitted with diarrhoea and required intravenous fluid and monitoring of electrolytes. He was very grateful for the care received, but one aspect must have stood out more clearly.

Department of Child Health, Royal Cornwall Hospital, Treliske, Truro, Cornwall TR1 3L, UK; matthew.thorpe@rcht.cornwall.nhs.uk

Competing interests: none declared
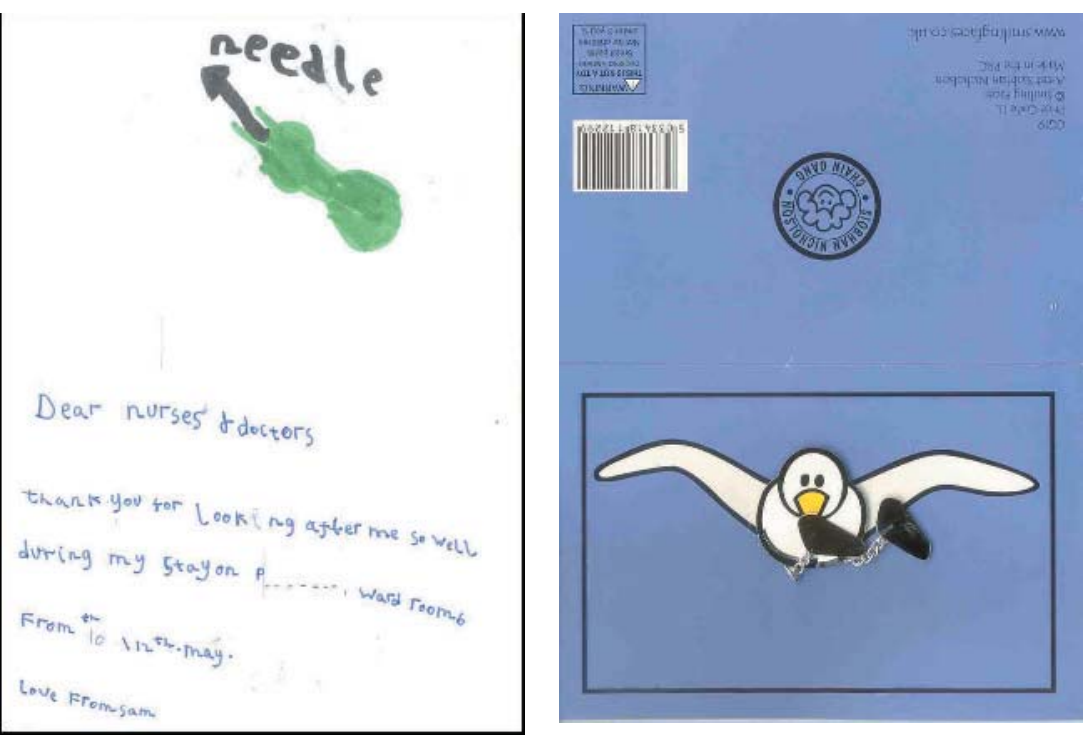